\title{
Expansão da educação superior, cursos de licenciatura e criação das novas universidades federais
}

\section{Resumo}

Arlete Maria Monte de Camargo Luciene das Graças de Miranda Medeiros Universidade Federal do Pará

Neste artigo objetivou-se analisar as repercussões das políticas da educação superior nas universidades públicas federais (criadas entre 2003 a 2014), afetadas por constrangimentos econômicos e financeiros, considerando, em especial, os cursos de licenciatura. Considera-se que as políticas sociais assumem a determinação de legitimar as relações sociais de produção, além do compromisso em atender às demandas da classe trabalhadora, por acesso à educação superior (CHESNAIS, 1995; PAULANI, 2008; NEVES, 2007). Realizou-se a revisão da literatura correlata, e recorreu-se à base de dados do Inep/MEC e aos sítios das universidades federais pesquisadas, onde se teve uma visão mais clara sobre a oferta de cursos em cada uma dessas IES. Entre os resultados, constam-se a construção de novas arquiteturas acadêmicas nos cursos de graduação e uma nova cultura acadêmico-institucional, apesar de ainda haver espaço para a tarefa de formar professores no espaço universitário, o que não 244 constitui prioridade em algumas instituições estudadas.

Palavras-chave: Educação superior. Expansão. Licenciaturasr.

\section{Expansion of higher education, undergraduate courses and creation of new federal universities}

\section{Abstract}

This article aims to analyze the repercussions of higher education policies in federal public universities (created between 2003 and 2014), affected by economic and financial constraints, especially considering undergraduate courses. It is considered that social policies assume the determination to legitimize the social relations of production, as well as the commitment to attend to the demands of the working class, for access to higher education (CHESNAIS, 1995; PAULANI, 2008; NEVES, 2007). the review of the related literature was done, and the INEP/ MEC database and the sites of the federal universities researched were used, where a clearer view was given on the offer of courses in each of these IES Among the results, the construction of new academic architectures in undergraduate courses and a new academic-institutional culture, although there is still room for the task of training teachers in the university space, which is not a priority in some institutions studied.

Keywords: Higher education. Expansion. Teacher training. 


\section{Expansión de la educación superior, cursos de Licenciatura y crea- ción de las nuevas Universidades Federales}

\section{Resumen}

En este artículo se objetivó analizar las repercusiones de las políticas de la educación superior en las universidades públicas federales (creadas entre 2003 a 2014), afectadas por limitaciones económicas y financieras, considerando en especial los cursos de licenciatura. Se considera que las políticas sociales asumen la determinación de legitimar las relaciones sociales de producción, además del compromiso en atender las demandas de la clase obrera, por acceso a la educación superior (CHESNAIS, 1995; PAULANI, 2008; NEVES, 2007). y se recurrió a la base de datos del INEP/MEC ya los sitios de las universidades federales investigadas, donde se tuvo una visión más clara sobre la oferta de cursos en cada una de esas IES, entre los resultados, se constata la construcción de nuevas arquitecturas académicas en los cursos de graduación y una nueva cultura académico-institucional, a pesar de que todavía hay espacio para la tarea de formar profesores en el espacio universitario, lo que no se constituye como prioridad en algunas instituciones estudiadas.

Palabras clave: Educación superior. Expansión. Licenciaturas.

\section{À guisa de introdução}

Pode-se dizer que a expansão da educação superior, fenômeno que vem se intensificando desde o final do século XX, tem sido marcada por constantes mudanças e tensões, que decorrem dentre outros aspectos pela redefinição do entendimento sobre o papel do Estado em relação às políticas sociais. Desde então, essas políticas passaram a se alinhar às orientações neoliberais difundidas sobretudo pelos organismos multilaterais, como é o caso do Banco Mundial (BM); foi disseminada uma racionalidade mercantil que não mais associa a oferta da educação superior como a de um bem universal, mas como um bem público, o qual pode ser acessado através de um serviço, como qualquer um outro, o que foi decisivo para a expansão de sua privatização.

A esse propósito, é importante situar o entendimento adotado pela Organização de Cooperação e Desenvolvimento Econômico (OCDE), que define como ensino superior um nível ou estágio de estudos realizado após o chamado ensino secundário' - a educação terciária. Nessa lógica, o entendimento sobre ensino superior é modificado, já que esses estudos poderiam ser realizados tanto em universidades, instituições de ensino superior públicas 
ou privadas, e institutos politécnicos. Interessante observar que outros tipos de cenários passaram a ser indicados, como os processos formativos que ocorrem em escolas secundárias, nos locais de trabalho ou cursos gratuitos através de tecnologia informática e uma grande variedade de entidades públicas e privadas (BANCO MUNDIAL, 2003).

Neste trabalho optou-se em abordar as repercussões das políticas da educação superior em curso nas universidades públicas federais criadas no período de 2003 a 2014 , considerando em especial os cursos de licenciatura. Sabe-se que essas instituições, nas últimas décadas, vêm sendo afetadas por constrangimentos econômicos e financeiros, o que contribui para mudanças quanto ao modelo de universidade, sua forma de atuação e prioridades.

Uma das principais referências para a constituição da universidade moderna foi o formato organizacional assumido pela Universidade de Berlim (Alemanha) no século XIX que teve como principal idealizador Humbold. Segundo Pereira (2009, p. 30), esse modelo se constitui em um momento histórico quando a ciência já assumia "[...] o aspecto estruturante do mundo moderno e os ditames epistemológicos rigidamente controlados pela igreja já não detinham a força que teve durante os dez séculos anteriores". A ideia 246 de universidade por ele defendida estava voltada para a sustentação do bem público e da nação e transcendeu a esfera alemã; autonomia e liberdade se constituíam princípios preponderantes sobre os demais.

Dessa forma, no entendimento da Humbold, a autonomia universitária deve ser desvinculada de qualquer força externa, acima de interesses do Estado, da religião, ou de qualquer outro poder político ou econômico. Para tal, são considerados fundamentais na constituição da universidade a liberdade didática, administrativa e financeira (PEREIRA, 2009).

Outra influência, igualmente importante, coexiste com o modelo humboldiano há algum tempo e defende outros propósitos para a universidade, procurando vinculá-la à sociedade e ao governo. Segundo esse modelo, a universidade deve estar voltada

[...] para as necessidades sociais, com a função de servir à nação e à finalidade de ser de utilidade coletiva, sociopolítica e socioeconômica. Nesta concepção, a universidade é tida principalmente como uma instituição instrumental de formação profissional e de formação política. É o modelo desenvolvido na França e nos países socialistas. Suas normas são emanadas do exterior, sua autonomia 
é relativa e seu controle pelas forças de poder é preponderante (PEREIRA, 2009, p. 32).

Esse entendimento é confirmado por autores como Charle e Verger (1996), os quais apontam o surgimento de verdadeiras escolas profissionais, algumas delas integradas às próprias universidades. Isso não impediu que fossem criadas com maior frequência fora das universidades "escolas especiais" ou "colégios profissionais".

Ferreira e Oliveira (2010), identificam os chamados modelos clássicos europeus de universidade: o modelo francês caracterizado pelo ensino público, leigo e padronizado, fortemente controlado pelo Estado e com ênfase na formação de profissionais para o mercado de trabalho e ocupações nos quadros do próprio Estado; o segundo, modelo alemão, em que a universidade de caracteriza pela autonomia e liberdade, contando para isso com o financiamento do estado, com a pretensão de se constituir em centro intelectual de alta cultura, de formação das elites e de qualidade no âmbito da pesquisa; e por último o modelo inglês, em que o ideal universitário considera o princípio da formação não utilitária e da formação integral mediante um método praticamente individual, em que a pesquisa científica, bem como a formação profissional, eram relegadas a um segundo plano.

Mais recentemente vem ganhando força o sistema universitário estadunidense, o qual se pauta por um caráter imediatista e utilitário para a nação. Sobre o assunto, esse modelo, Ferreira e Oliveira dizem que:

[...] começou a ser visto como um sistema competitivo, desde a metade do século XX, por caracterizar-se, entre outros fatores, pela diversificação e hierarquização de IES que atendem a papéis diferenciados. Nesse sistema, estão presentes tanto universidades tradicionais, que realizam pesquisa e ensino e recebem uma elite econômica e cultural, quanto uma gama de IES que oferecem cursos curtos e profissionalizantes para as camadas menos favorecidas da sociedade (FERREIRA; OLIVEIRA, 2010, p.54).

Esses modelos irão predominar no século XX, ora com a preponderância de um, ora de outro modelo, o que irá influenciar igualmente a realidade brasileira. Ultimamente, vem ganhando força o entendimento de que as atividades desenvolvidas nas universidades, "[...] devem ter - e devem demonstrar através de indicadores quantitativos (de preferência) - um impacto econômico 
e social positivo nas sociedades ao redor delas" (McCOWAM; SCHENDEL, 2015 , p. 20).

O entendimento da educação como uma mercadoria regulada pelas leis do mercado ganha força no contexto mundial, tendo em vista o movimento de internacionalização da economia, no qual a educação passa a ser objeto de negociação ao lado de outros serviços, o que tem levado à presença de conglomerados educacionais importantes na educação superior brasileira.

Em concomitância, são adotadas no cenário internacional reformas estruturais por países em desenvolvimento, destacando-se medidas direcionadas à educação, de modo geral, e, em especial, à educação superior. Segundo essas orientações, os sistemas de ensino devem se tornar mais diversificados e flexíveis, visando a uma maior competitividade do setor privado em face da necessidade de contenção dos gastos públicos, decorrente da reconfiguração do Estado brasileiro (MANCEBO; MAUÉS; CHAVES, 2006).

Concernente à formação de professores, no processo de criação de instituições universitárias no Brasil, tanto a Universidade de São Paulo como a Universidade do Distrito Federal (Rio de Janeiro), incluíam unidades voltadas para a formação de professores, o que passou a ser igualmente válido em relação a outras universidades que se sucederam.

Charlot e Silva (2010) afirmam que as universidades sempre tiveram como uma das suas tarefas centrais a formação de professores para o chamado ensino secundário ${ }^{2}$. Só recentemente é que a formação de professores, em nível superior para os anos iniciais da escolarização, passou a ser exigida com a Lei de Diretrizes e Bases da Educação Nacional, n 9.394, de 20 de dezembro 1996, o que irá levar a uma expansão na oferta de cursos direcionados para a formação de professores dessa etapa, sobretudo em instituições de educação superior privadas e na modalidade a distância.

São significativos os problemas usualmente enfrentados pelos cursos de licenciatura como o caso dos cursos noturnos e da pouca atratividade da carreira docente, o que pode favorecer a evasão nesses cursos, já que os alunos se sentem desestimulados a prosseguir (MINDAL; GUÉRIOS, 2013). Isso, entretanto, não libera os governos em suas várias esferas da responsabilidade com a formação de quadros que, em sua maioria, irão atuar no aparelho estatal, como é o caso dos professores das redes públicas de ensino. 
Nesse sentido, este artigo foi elaborado com base no projeto "Políiticas da Expansão da Educação Superior no Brasil"3 em curso pela Rede Universitas/Br, e procurou investigar as políticas de expansão do ensino superior na atualidade, tendo como referência as mudanças econômicas ocorridas nas quatro últimas décadas, que culminaram no "regime de acumulação com dominância de valorização financeira" (CHESNAIS, 1996), e que no Brasil irá repercutir a partir de 1995, como um ambiente institucional voltado para o controle dos gastos do Estado, fim da regulação estatal e liberdade máxima para o capital (PAULANI, 2008).

O foco do estudo voltou-se para a oferta de cursos de licenciatura no elenco de cursos ofertados pelas dezoito universidades federais criadas no período de 2003 a 2014, nos governos Lula da Silva e Dilma Rousseff, política materializada com o advento do Programa de Apoio a Planos de Reestruturação e Expansão das Universidades Federais - Reuni, instituído pelo Decreto $n^{\circ}$ 6.096, de 24 de abril de 2007, que injetou aporte financeiro nas universidades públicas federais mediante contratos de gestão que deveriam ser assinados por essas Instituições de Educação Superior - IES.

Para analisar essa política, priorizou-se o entendimento de Neves (2009), para quem uma política educacional

[...] em uma dada formação social concreta, no mundo contemporâneo, é determinada pelo estágio de desenvolvimento das forças produtivas e das relações de produção e, também, pelo embate provisório das várias propostas educacionais em disputa pela hegemonia no Estado, em sentido estrito, e na sociedade civil (NEVES, 2009, p. 209).

Isso significa dizer que as políticas sociais, além de assumir a determinação de legitimar as relações sociais de produção, acabam por assumir o compromisso em atender às demandas da classe trabalhadora, inclusive as que decorrem dos processos de formação de professores, o que irá depender da correlação de forças em uma dada sociedade.

Além disso, procurou-se problematizar a continuidade da tarefa de formação de professores da educação básica, que vem sendo priorizada desde o surgimento das universidades brasileiras, considerando as principais evoluções contemporâneas da educação superior marcadas pela internacionalização, mercantilização e diferenciação. Ao mesmo tempo, iremos sinalizar 
para algumas tendências observadas nessas universidades criadas neste século o que nos permitirá projetar como será a formação dos docentes nas universidades públicas do século XXI.

trabalho foi elaborado com base na revisão da literatura correlata envolvendo as seguintes prioridades: expansão da educação superior, cursos de licenciatura, políticas educacionais (LIMA, 2007; MANCEBO, MAUÉS, CHAVES, 2006; SGUISSARDI, 2014). Em relação aos procedimentos metodológicos, recorreu-se à base de dados do Instituto Nacional de Estudos e Pesquisas Educacionais Anísio Teixeira, do Ministério da Educação, procurando identificar dados secundários relativos ao número de Instituições de Educação Superior (IES) por Organização Acadêmica, Categoria Administrativa que nos permitisse identificar a evolução dessas IES no período estudado. Além disso, foram realizadas consultas aos sítios das universidades federais pesquisadas, onde se teve uma visão mais clara sobre a oferta de cursos em cada uma dessas IES, em especial se essa oferta incluía os cursos de licenciatura.

\section{0 definidores das políticas educacionais}

Em se tratando de expansão da educação superior brasileira, é importante ressaltar que o Brasil é um país marcado por heterogeneidades regionais e sociais, as quais refletem, em certa medida, as mudanças globais, já referidas, que se intensificaram a partir da década de 1970 com o esgotamento do taylorismo/fordismo que gerou a crise do modelo de Estado keynesian/ fordista.

No caso brasileiro, a situação foi mais grave porque o país carregava, ainda, toda a herança nefasta da ditadura militar que se estendeu de 1964 a 1985, quando o poder estatal militar criminalizou os movimentos sociais organizados apartando a sociedade de qualquer participação política. Paradoxalmente, foi um período de expansão da educação superior, considerada estratégica pelos governos militares porque foi necessária a expansão da qualificação de mão de obra para sustentar o desenvolvimento industrial previsto. Isso corrobora a premissa de que o fenômeno da expansão da educação superior, embora tardia, no Brasil, tem sido em razão dos interesses dos governos de plantão que têm colocado o Estado sempre a serviço do capital e 
utilizado a educação como instrumento para conformar a classe trabalhadora aos seus ditames.

Nos 21 anos da ditadura militar, foram criadas 14 (quatorze) universidades públicas, período marcado pelo amordaçamento da universidade, sobretudo político, em que a educação superior sofreu profundas mudanças implementadas pela reforma universitária, amparada pela Lei n 5.540, de 28 de novembro de 1968, que alterou o arcabouço jurídico e pedagógico da educação superior. Essa Lei estruturou uma concepção de universidade que defendia "[...] uma educação utilitária para o progresso da nação e da sociedade" (MENEGUEL apud MEDEIROS, 2012, p. 58) que repercutiu em alterações na forma de organização administrativa e pedagógica, nos valores, objetivos e fins que passaram a orientar as funções de ensino, pesquisa e extensão nas universidades públicas federais. Houve expansão da pós-graduação que, se por um lado, criou uma elite de ideólogos do sistema autoritário; por outro lado, oportunizou o surgimento de um grupo de intelectuais críticos que muito contribuiu, alguns com suas vidas, para a redemocratização do país.

Os anos de 1980 trouxeram o aprofundamento da crise do capital iniciada na década anterior, caracterizada como uma crise do Estado de BemEstar Social, particularmente nos países europeus. O capital, em seu processo metabólico destrutivo, se reestrutura resgatando suas bases liberais, capitaneado nos Estados Unidos por Ronald Reagan e na Inglaterra por Margaret Thatcher, que passaram a defender mudanças de rota em suas políiticas sociais com a justificativa de que essas políticas, que garantiam direitos aos trabathadores, precisavam de altos investimentos os quais, suas economias não poderiam mais suportar porque arrastariam seus Estados à crise. Esses países que aderiram ao neoliberalismo como se fosse a única saída, criaram mecanismos para disseminá-lo em toda a América Latina, contexto geopolíitico em que o Chile se constituiu num "laboratório de experiências neoliberais" a serem replicadas na região.

No Brasil, os governos de Collor (1990-1992) e de Itamar Franco (1993-1994), de acordo com Lima (2007, p. 88) constituíram a primeira fase das reformas neoliberais quando se inicia um processo de adaptação do país ao Consenso de Washington, espaço onde foram forjadas 10 regras básicas para promover o "ajuste macroeconômico" sobretudo dos países latino-americanos, o que foi incorporado pelos governos subsequentes. 
Em 1995, no governo de Fernando Henrique Cardoso, que foi ministro no Governo ltamar Franco, tem início a Reforma do Aparelho Administrativo do Estado, com desdobramentos em políticas para a educação superior, alinhadas às orientações neoliberais veiculadas, particularmente, pelo Banco Mundial que tiveram, entre outros, o objetivo de disseminar uma racionalidade mercantil que projetasse a educação superior como mais uma mercadoria, cimentado o caminho para a expansão de sua privatização. Tanto nos documentos oficiais do governo, quanto na legislação, como na Lei n 9.394, de 20 de dezembro de 1996, a estratégia foi o incentivo para que as instituições públicas diversificarem suas fontes de financiamento, bem como, o convencimento à população de que a educação superior deveria ser paga.

Algumas propostas e políticas, iniciadas em governos anteriores, foram acatadas e implementadas, posteriormente, pelos governos de Lula da Silva (2003-2010) e Dilma Rousseff (201 1-2014-2015) numa opção clara pela privatização com a utilização de recursos financeiros do Fundo Público para beneficiar os empresários da educação. Dilma Rousseff sofreu processo de impeachment, articulado e levado a efeito por um golpe das forças conservadoras aliadas ao parlamento, ao judiciário e à mídia empresarial que 252 culminou com seu afastamento, após haver sido cassada pelo Senado Federal, em 31 de setembro de 2016 por 61 votos favoráveis e 20 contrários. Porém, não é demais lembrar que, em seu período de governo, a expansão iniciada no governo Lula, sofreu um acentuado processo de precarização em razão dos cortes brutais no orçamento para a educação, desde 2014 , visando garantir o superávit primário e assegurar o pagamento dos serviços da dívida pública.

De acordo com a LDB (Lei n 9.394, de 20 de dezembro de 1996), a educação superior se estrutura em dois setores: o público que contempla as IES federais, estaduais e municipais, e o privado com as IES confessionais, comunitárias e filantrópicas e particulares com fins lucrativos. Quanto à modalidades de organização acadêmica, a LDB se refere, no Art. 52, às Universidades como "instituições pluridisciplinares de formação de quadros profissionais de nível superior, de pesquisa, de extensão e de domínio e cultivo do saber humano...", porém são os Decretos, Portarias Ministeriais e outras Normativas que regulamentam a LDB, que vão definir a organização acadêmica das IES, tais como: o Decreto n ${ }^{\circ}$ 5.773, de 9 de maio de 2006, conhecido como Decreto - Ponte, que revogou os Decretos n ${ }^{\circ} 1.845$, de 28 de março de 1996; o n³.860, de 9 de julho de 200 1; o n³.864, de 11 de julho de 200 1; o n 
3.908, de 4 de setembro de 200 1, e o n 5.225, de $1^{\circ}$ de outubro de 2004 . Apresenta no Art. 12 a organização das instituições de educação superior em: I- Faculdades, II - Centros Universitários e III - Universidades, excluindo do Decreto anterior (n ${ }^{\circ} 3.860 / 2001$ ), os Institutos ou Escolas Superiores; Portaria Normativa $n^{\circ} 40$ de 12 de dezembro de 2007 classifica as IES de acordo com sua organização acadêmica em: I- Faculdades; II- Centros Universitários; III- Universidades; IV- Institutos Federais de Educação, Ciência e Tecnologia; V- Centros Federais de Educação Tecnológica; Decreto nº 6.096/2007, de 24 de abril de 2007, que estabelece diretrizes para o processo de integração de instituições federais de educação tecnológica, para fins de constituição dos Institutos Federais de Educação, Ciência e Tecnologia (IFET), no âmbito da Rede Federal de Educação Tecnológica.

Os dados do Instituto Nacional de Estudos e Pesquisas Educacionais Anísio Teixeira - Inep - que a cada ano oferece dados empíricos sobre a expansão das instituições de ensino superior públicas e privadas, número de matrículas e de cursos presenciais e a distância, funções docentes, concentração de cursos, entre outros, mostra que, nesses últimos anos tem havido redução de IES pública (federal, estadual e municipal), privadas sem fins lucrativos (comunitárias e confessionais) e uma crescente e rápida expansão das IES privadas particulares com (fins lucrativos). Esse último dado demarca a opção dos governos recentes por uma educação superior de caráter mercantil, que tende a se acentuar no governo ilegítimo de Temer (2016-2017) e de seu Ministro da Educação Mendonça Filho, defensor do fim da gratuidade nas universidades públicas federais.

A evolução do número de IES por organização acadêmica e categoria administrativa no período que sucede à $\operatorname{LDB} n^{\circ} 9.394$, de 20 de dezembro de 1996, pode ser assim compreendida: no ano de 1996, ano de aprovação dessa Lei, havia 922 instituições de educação superior (IES), sendo que, dessas, 211 públicas e 711 privadas, com predomínio de 77,1\% do setor privado.

Importante lembrar que a partir dessa Lei foi atingida a base organizativa da educação superior. A esse respeito, Morosini, Franco e Segenreich (201 1) afirmam que a expansão da educação superior, no princípio da diversidade, incorpora diferentes formatos de organização institucional e acadêmica; além das universidades, passa a incluir centros universitários, institutos, faculdades, entre outros. Esses formatos configuram diversas modalidades terminais, 
diplomas ou certificados, e através de diferentes ofertas, presenciais, a distância e semipresenciais.

$\bigcirc$ processo de expansão, iniciado desde então, está ancorado no entendimento da educação superior como um serviço, e não mais como bem público (entendimento adotado pela $O C D E$ ), cuja obtenção pode se dar a partir das opções disponíveis no mercado, para o que muito contribuiu a expansão da privatização desse nível de ensino, e a renúncia fiscal que incentivou o segmento privado a investir nessa etapa da formação.

Além da força dessa orientação, há que se considerar que, no ano de 2015, a porcentagem de matrículas na educação superior em relação à população de 18 a 24 anos era de 34,6\%, e, entre as metas previstas no Plano Nacional de Educação aprovado, destaca-se a Meta 12 que prevê "Elevar a taxa bruta de matrícula na educação superior para 50\% e a taxa líquida para 33\% da população de 18 a 24 anos, assegurando a qualidade da oferta" (BRASIL, 2015). Essa situação indica que ainda há espaço para a ampliação da oferta, o que encontra seus limites na diminuição do fundo público, e na capacidade de pagamento da população brasileira.

\section{A criação de novas universidades federais no período de 2003 a 2014}

Em 2003, quando inicia o primeiro mandato do presidente Luís Inácio Lula da Silva, 51 ,6\% eram 1859 IES, sendo que, dessas, 207 eram instituições públicas e 1652 privadas. Em 2010, último ano de seu mandato, havia 2.378 IES sendo 278 IES públicas e 2.010 privadas (MEC/INEP/DEED - Censo da Educação Superior). Esses dados confirmam a tendência de ampliação do setor privado, mas indicam igualmente uma ampliação do setor público, o que pode ser explicado pela criação dos Centros Federais e Institutos Federais de Educação Superior, além do advento do Reuni ${ }^{4}$ (Decreto nº 6.096, de 24 de abril de 2007). Esse programa, vigente a partir de 2008, injetou aporte financeiro nas universidades públicas federais e contribuiu para a criação de 14 novas universidades federais nesse período.

Em relação ao período de 2011 a 2014, o primeiro mandato da presidente Dilma Rousseff guarda algumas particularidades: deu continuidade ao REUNI, criando quatro novas universidades federais: Universidade Federal do Oeste da Bahia, Universidade Federal do Sul da Bahia, Universidade Federal 
do Sul Sudeste do Pará; Universidade Federal do Cariri, além da continuidade das práticas gerenciais que intensificam o discurso do "fazer mais com menos". Outra característica foi o avanço na implantação de Bacharelados Interdisciplinares, que podem ser considerados como uma nova arquitetura acadêmica nos cursos de graduação. Quanto ao crescimento das IES por Organização Acadêmica e Categoria Administrativa, observou- se o seguinte:

Em 2011 , havia 2.365 IES sendo que, dessas, 284 eram públicas e 2.081 privadas; em 2014 , foram registradas 2.368 IES, sendo que, dessas, 298 eram públicas e 2.070 privadas, tendo se observado um maior crescimento das faculdades no segmento privado, que, em 2014, foram 1850, contra 136 públicas (BRASIL, 2014).

No caso da expansão da educação superior pública, além da criação das universidades federais já referidas, observou-se, igualmente, um movimento de criação de novos campi nas regiões Norte e Nordeste do país, o que ratifica a meta do Reuni de expandir a interiorização da educação superior (BRASIL, 2013).

No entanto, essa expansão vem sendo marcada pela precarização das condições de trabalho, e o objetivo de criar uma "cultura acadêmica", no interior dessas regiões, ficou a desejar porque a maioria dos docentes não fixaram residência nos campi, criando-se arranjos curriculares em que as aulas são ministradas em "sistema blocado", como observado, na Universidade Federal do Pará, na Região Norte, nos campi próximos a Belém, em que professores permanecem, no máximo, 15 dias. Assim, contribuem para o enfraquecimento da indissociabilidade entre ensino, pesquisa e extensão e para o fortalecimento de uma universidade focada no ensino (MEDEIROS, 2012).

A tabela a seguir evidencia a expansão da educação superior pública, no que diz respeito às universidades federais, no período analisado, compreendido entre os anos de 2003 a 2014. 
Tabela 1

Expansão das universidades federais nas regiões brasileiras por IFES e campi 2002 a 2014

\begin{tabular}{|c|c|c|c|c|c|}
\hline \multicolumn{5}{|c|}{ IFES } & \multicolumn{2}{c|}{ CAMPUS } \\
\hline Região & 2002 & 2014 & $\%$ crescimento & 2002 & 2014 \\
\hline NORTE & 8 & 10 & $25 \%$ & 24 & 56 \\
\hline NORDESTE & 12 & 18 & $50 \%$ & 30 & 90 \\
\hline SUL & 6 & 11 & $83 \%$ & 29 & 63 \\
\hline SUDESTE & 15 & 19 & $27 \%$ & 46 & 81 \\
\hline CENTRO-OESTE & 4 & 5 & $25 \%$ & 19 & 31 \\
\hline
\end{tabular}

Fonte | SIMEC/MEC/ Balanço Social Sesu (2002-2014)

De acordo com essa tabela, no que diz respeito ao crescimento de novas instituições, observa-se o predomínio da região Sul, seguido da região Nordeste; em relação à ampliação dos campi, esse ocorreu, prioritariamente, na região Nordeste (200\%), seguida das regiões Norte e Sul.

Sabe-se que, no processo de expansão da educação superior, construído historicamente, alguns argumentos têm sido decisivos para a definição de prioridades: a necessidade de democratização do acesso, além de um apelo forte que é o que vincula a oferta de educação superior ao desenvolvimento regional. Mais adiante será possível visualizar o quadro de instituições por região e analisar mais adequadamente essa expansão.

Como já referido, nos oito anos do governo Lula da Silva, com o advento do Reuni foram criadas 14 novas universidades públicas federais e mais $\mathrm{O} 4$ no governo Dilma Rousseff. As novas universidades criadas seguiram uma nova regulação da política de expansão da educação superior, a qual está relacionada com a matriz econômica capitalista que defende uma concepção de educação que se conecta direta e indiretamente com concepções presentes no cenário mundial. Têm como centralidade uma visão pragmatista e mercantil da educação superior e que desloca a concepção da educação superior como direito universal para concebê-la como "bem público".

Compõe o conjunto de regulações pós-burocráticas que vêm sendo impostas à educação superior incidindo, sobretudo, na produção do conhecimento capitalista que forjou uma regulação educacional para a América Latina 
assentada no tripé: gestão (empresarial) avaliação (de resultados) e financiamento. Esses pressupostos, presentes no Processo de Bolonha e no "Nova Universidade", a partir do Reuni, passaram a orientar, alterando, o modus operandi das universidades públicas federais, no Brasil (MEDEIROS, 2012).

Entre as mudanças acadêmicas, a partir do Reuni, nas novas universidades federais, destacam-se os Bacharelados Interdisciplinares, que são uma nova arquitetura acadêmica dos cursos de graduação da educação superior para evitar a profissionalização precoce. Caracterizam-se por uma reestruturação dos currículos desses cursos que passam a se organizar por grandes áreas de conhecimentos entendidos como campos de saberes, práticas e tecnologias. Fundamentam-se nos princípios da flexibilização curricular, da inovação tecnológica; reconhecimento, validação e certificação de conhecimentos, competências e habilidades e do estímulo à iniciativa individual. Têm como meta desenvolver uma educação superior que forneça as bases da inovação, da competitividade e da produtividade via um sistema uniforme de créditos, organizado a partir de ciclos de estudos com processos de ensino centrados na competência e avaliação dos alunos, adotando um modelo curricular que se aproxima ao praticado, em alguns casos, nos Estados Unidos, no Reino Unido e no Canadá.

Em 12 de abril de 2010, o então Ministro da Educação, pela Portaria $n^{\circ} 383 /$ SESu/MEC, instituiu um Grupo de Trabalho que elaborou um documento intitulado "Referenciais Orientadores para os Bacharelados Interdisciplinares e Similares" referenciado no Universidade Nova, para que as universidades federais fizessem as alterações na estrutura acadêmica de seus cursos de graduação.

A indução dessa forma de organização curricular irá se expressar em, pelo menos, oito universidades federais recém-criadas no governo Lula ${ }^{5}$; essas instituições organizaram o ensino de graduação sob essa arquitetura acadêmica em que os currículos flexíveis são organizados com base em um sistema uniforme de créditos, com ciclos de estudos, que possibilitem mobilidade intra e interinstitucional dos estudantes com o aproveitamento desse conjunto de créditos.

Seguindo esse fio condutor, cada universidade federal brasileira "com base em sua autonomia" deve buscar "seu caminho de desenvolvimento" a partir do Reuni, uma regulação da expansão da educação superior "que oferece 
às instituições condições para repensar sua estrutura acadêmica e seu desenho institucional" (BRASIL, 2007a, p. 27). Nas Diretrizes do Reuni estão firmados os eixos orientadores da estrutura curricular dos cursos de graduação: flexibilização, diversificação e interdisciplinaridade, visando à formação de profissionais articulados com as exigências do mercado.

Até 2014, as 18 novas universidades federais, criadas nos governos Lula da Silva e Dilma Rousseff, já haviam adotado os Bacharelados Interdisciplinares - Bl's, em seus Cursos de Graduação. Segundo dados da SESU/ MEC, "[...] os Bacharelados Interdisciplinares (Bl's), se constituem em cursos superiores de natureza geral, ou seja, não profissional, organizados por grandes áreas do conhecimento e que conferem um diploma de graduação" e um dos resultados esperados é que

[...] os egressos sejam capazes de responder a novas demandas da sociedade contemporânea, atuando em áreas de fronteira e de interface entre diferentes disciplinas e campos de saber, trabalhando em equipe e em redes, comprometidos com a sustentabilidade nas relações entre ciência, tecnologia, economia, sociedade e ambiente e apresentando postura flexível e aberta em relação ao mundo do trabalho (BRASIL, 2014).

Segundo Medeiros (2012), a partir do Reuni, observa-se um avanço de uma concepção de educação superior "mais fiel e alinhada às orientações da matriz neoliberal, sustentadora do modo de produção capitalista que desumaniza toda e qualquer relação social" (MEDEIROS, 2012, p. 286). Ademais, verifica-se uma maior intensificação do trabalho docente, e, em consequência, a precarização do trabalho docente que, além das alterações nas relações trabalhistas ${ }^{6}$ se expressam na deterioração das condições objetivas e subjetivas as quais o trabalho docente é realizado.

Agora, passa-se a traçar um quadro que expresse a criação das universidades federais, tanto as criadas no governo do Presidente Lula da Silva, quanto da presidente Dilma Rousseff, procurando, em seguida, quais as principais características desse processo de expansão. 


\section{Quadro 1}

Universidades Federais criadas no Governo Lula da Silva, 2003 a 2010

\begin{tabular}{|c|c|c|c|}
\hline IFES & Nome da IFES & Região & Lei de criação \\
\hline UNIFAL & $\begin{array}{l}\text { Universidade Federal de } \\
\text { Alfenas }\end{array}$ & Sudeste & $\begin{array}{l}\text { Lei } n^{\circ} 11.154 \mathrm{de} \\
29 / 07 / 2005\end{array}$ \\
\hline UFVJM & $\begin{array}{l}\text { Universidade Fed. dos Vales } \\
\text { Jequitinhonha e Mucuri }\end{array}$ & Sudeste & $\begin{array}{l}\text { Lei } n^{\circ} 11.173 \mathrm{de} \\
06 / 09 / 2005\end{array}$ \\
\hline UFTM & $\begin{array}{l}\text { Universidade Federal do } \\
\text { Triângulo Mineiro }\end{array}$ & Sudeste & $\begin{array}{l}\text { Lei } n^{\circ} 11.152 \mathrm{de} \\
29 / 07 / 2005\end{array}$ \\
\hline UFERSA & $\begin{array}{l}\text { Universidade Federal Rural } \\
\text { do Semiárido }\end{array}$ & Nordeste & $\begin{array}{l}\text { Lei } n^{\circ} 11.155 \mathrm{de} \\
29 / 07 / 2005\end{array}$ \\
\hline UTFPR & $\begin{array}{l}\text { Universidade Tecnológica } \\
\text { Federal do Paraná }\end{array}$ & Sul & $\begin{array}{l}\text { Lei } n^{\circ} 11.184 \mathrm{de} \\
07 / 01 / 2005\end{array}$ \\
\hline UFABC & $\begin{array}{l}\text { Fundação Universidade } \\
\text { Federal do ABC }\end{array}$ & Sudeste & $\begin{array}{l}\text { Lei } n^{\circ} 11.145 \mathrm{de} \\
26 / 07 / 2005\end{array}$ \\
\hline UFGD & $\begin{array}{l}\text { Fundação Universidade } \\
\text { Fed. de Grande Dourados }\end{array}$ & Centro Oeste & $\begin{array}{l}\text { Lei } n^{\circ} 11.153 \mathrm{de} \\
29 / 07 / 2005\end{array}$ \\
\hline UFRB & $\begin{array}{l}\text { Universidade Federal do } \\
\text { Recôncavo da Bahia }\end{array}$ & Nordeste & $\begin{array}{l}\text { Lei } n^{\circ} 11.151 \mathrm{de} \\
29 / 07 / 2005\end{array}$ \\
\hline UFCSPA & $\begin{array}{l}\text { Fundação Univ. Fed. de } \\
\text { Ciências da Saúde de Porto } \\
\text { Alegre }\end{array}$ & Sul & $\begin{array}{l}\text { Lei } \mathrm{n}^{\circ} 11.641 \mathrm{de} \\
11 / 01 / 2008\end{array}$ \\
\hline UNIPAMPA & $\begin{array}{l}\text { Fundação Universidade } \\
\text { Federal do Pampa }\end{array}$ & Sul & $\begin{array}{l}\text { Lei } \mathrm{n}^{\circ} 11.640 \mathrm{de} \\
11 / 01 / 2008\end{array}$ \\
\hline UFFS & $\begin{array}{l}\text { Universidade Federal da } \\
\text { Fronteira Sul }\end{array}$ & Sul & $\begin{array}{l}\text { Lei no } 11.029 \text { de } \\
15 / 09 / 2009\end{array}$ \\
\hline UFOPA & $\begin{array}{l}\text { Universidade Federal do } \\
\text { Oeste do Pará }\end{array}$ & Norte & $\begin{array}{l}\text { Lei } n^{\circ} 12.085 \mathrm{de} \\
05 / 11 / 2009\end{array}$ \\
\hline UNILA & $\begin{array}{l}\text { Universidade Federal } \\
\text { da Integração Latino } \\
\text { Americana }\end{array}$ & Sul & $\begin{array}{l}\text { Lei } \mathrm{n}^{\circ} 12.189 \mathrm{de} \\
12 / 01 / 2010\end{array}$ \\
\hline UNILAB & $\begin{array}{l}\text { Universidade da Integração } \\
\text { Internacional da Lusofonia } \\
\text { Afro-Brasileira }\end{array}$ & Nordeste & $\begin{array}{l}\text { Lei } n^{\circ} 12.289 \mathrm{de} \\
20 / 07 / 2010\end{array}$ \\
\hline
\end{tabular}

Fonte: Sítios das Universidades Federais. 
Nesse período, observou-se a criação de 14 universidades federais, sendo que, dessas, 09 universidades federais nas regiões Sul e Sudeste; as outras cinco criadas localizam-se três na região Nordeste, uma na região Centro-Oeste e uma na região Norte. Interessante observar que predominou a criação de novas instituições nas regiões Sul e Sudeste, as quais apresentam um quadro diferenciado em relação às demais regiões do país no que tange à oferta de educação superior. Isso leva a crer que outros critérios foram considerados, como as barganhas políticas que, em geral, orientam a definição de prioridades, a formação de quadros para atendimento às demandas do setor produtivo, muito mais do que o apelo à democratização dessa etapa da formação.

Quadro 2

Universidades federais criadas no Governo Dilma Rousseff, 2011 a 2014

\begin{tabular}{|c|c|c|c|}
\hline IFES & Nome da IFES & Região & Lei de criação \\
\hline UFOB & $\begin{array}{c}\text { Universidade Federal do } \\
\text { Oeste da Bahia }\end{array}$ & Nordeste & $\begin{array}{c}\text { Lei } n^{\circ} 12.825, \text { de } \\
05 / 06 / 2013 .\end{array}$ \\
\hline UFESBA & $\begin{array}{c}\text { Universidade Federal do } \\
\text { Sul da Bahia }\end{array}$ & Nordeste & $\begin{array}{c}\text { Lei } n^{\circ} 12.818, \text { de } \\
05 / 06 / 2013 .\end{array}$ \\
\hline UNIFESSPA & $\begin{array}{c}\text { Universidade Federal do } \\
\text { Sul Sudeste do Pará }\end{array}$ & Norte & $\begin{array}{c}\text { Lei } n^{\circ} 12.824, \text { de } \\
05 / 06 / 2013 .\end{array}$ \\
\hline UFCA & $\begin{array}{c}\text { Universidade Federal do } \\
\text { Cariri }\end{array}$ & Nordeste & $\begin{array}{c}\text { Lei } n^{\circ} 12.826, \text { de } \\
05 / 06 / 2013 .\end{array}$ \\
\hline
\end{tabular}

Fonte: Sítio das Universidades Federais.

Nesse período, foi privilegiada a criação de universidades federais na região Nordeste, com a criação de três universidade e apenas uma na região Norte do país, diferentemente do período anterior quando foi priorizada a criação de universidades nas Regiões Sul e Sudeste do país. $\bigcirc$ que se percebe é que a expansão ocorreu em um ritmo diferente do governo anterior, e teve uma orientação diferenciada quando priorizou a criação de universidades na região Nordeste e Norte. Essas IES foram criadas a partir da elevação de antigos campi, como foi o caso da UFOB e da UNIFESSPA, os quais faziam parte respectivamente da Universidade Federal da Bahia e da Universidade Federal do Pará. 
Em relação ao período estudado, compreendido entre os anos de 2003 e 2014 , sete universidades foram criadas em estados das Regiões Sul e Sudeste, duas na Região Norte, seis na Região Nordeste e apenas uma na Região Centro-Oeste. Isso, provavelmente, pode ter contribuído para a manutenção de assimetrias regionais no acesso à educação superior pública, já que as Regiões Sul e Sudeste, são as que, historicamente, têm maior acesso à educação superior em comparação às demais regiões brasileiras.

\section{A oferta de cursos de licenciatura nas novas universidades federais}

Conforme visto, a criação de novas universidades federais sob a orientação do Reuni (Decreto n 6096, de 24 de abril de 2007) foi uma política priorizada nos governos Lula da Silva e Dilma Roussef e que tinha, entre seus objetivos: elevar a taxa de conclusão dos cursos de graduação para 90\%; aumentar o número de estudantes de graduação nas universidades federais; aumentar o número de alunos por professor em cada sala de aula da graduação; diversificar as modalidades dos cursos de graduação, através da flexibilização dos currículos, da criação dos cursos de curta duração e/ou ciclos (básico e profissional) e da educação a distância, incentivando a criação de um novo sistema de títulos e a mobilidade estudantil entre as instituições (públicas e/ou privadas) de ensino.

$\bigcirc$ processo expansionista nas universidades federais ocorre em um contexto de restrições orçamentárias, o que contribui para pôr em xeque a questão da autonomia universitária, já que as ações de cada uma dessas IES criadas ficam limitadas à realização de novos concursos públicos para a formação de quadros, aquisição de equipamentos, necessários a realização das atividades acadêmicas, além do predomínio das atividades de ensino, em detrimento da pesquisa e extensão. Essa constatação leva a inferir que a expansão realizada com base nas características já descritas, pode ter contribuído para mudanças no padrão de instituições universitárias, quando comparada às universidades tradicionais de ensino, pesquisa e extensão.

De modo geral, pode-se dizer que o processo de criação de universidades federais foi marcado por duas grandes tendências: a interiorização e a internacionalização. A interiorização das ações das universidades federais 
Expansão da educação superior, cursos de licenciatura e criação das novas universidades federais

pode ser confirmada a partir da localização da grande maioria das universidades criadas. Segundo documento elaborado pelo MEC, a interiorização da oferta de educação superior "[...] é essencial para combater o desequilíbrio no desenvolvimento regional e atingir estudantes sem condições de se deslocar para outras regiões" (BRASIL, 2014).

Tal afirmação se sustenta no fato de que, em 2003, das 44 universidades federais existentes, 29 estavam situadas na capital, e 14 no interior. Em 2014 , o número de universidades federais passou para 63, sendo que, dessas, 31 estavam situadas na capital, e 32 no interior dos estados brasileiros. Isso, sem dúvida, é positivo e contribui para alterar ainda que, parcialmente, a realidade da população que vive no interior dos estados, apesar das limitações materiais que cercam o surgimento dessas instituições

Outra tendência é a de criação de universidades com perfil internacionalista, o que reflete uma opção igualmente feita pelos governos federais no período em análise. Segundo documento elaborado pelo MEC, a SESu desenvolveu um processo de integração regional e internacionalização da educação superior, por meio da criação de quatro universidades federais localizadas nos estados fronteiriços da região Sul do Brasil, além de possibilitar 262 intercâmbio entre o Brasil e os países da América Latina e os países falantes da língua portuguesa em outros continentes, como África e Ásia. O processo de internacionalização da educação superior que implica a troca de experiências e investigação cientifica entre países, vem sendo ressignificado de modo a representar esforços sistemáticos feitos pelas instituições visando responder às exigências e desafios relacionados à globalização da sociedade, da economia e dos mercados (MOROSINI, 2004; FERREIRA; OLIVEIRA, 2010 ; AZEVEDO, 2015; MANCEBO; RIBEIRO, 2012 ; SILVA JÚNIOR, 20151.

A preocupação com a formação de professores não está expressa entre os objetivos do Reuni, apesar de outras políticas na atualidade se voltarem, especificamente, sobre a questão como é o caso do Parfor. Interessante observar que a oferta de cursos de licenciatura no Brasil se constituiu, historicamente, em uma tarefa central assumida pelas universidades, como já observado por Charlot e Silva (2010), inclusive quando as primeiras instituições universitárias foram criadas, caso da Universidade de São Paulo e a Universidade do Distrito Federal (Rio de Janeiro). 
Com base em Camargo e Castro (2016), o que se percebe é que, na atualidade, essa tarefa vem sendo assumida por outras IES, como é o caso das Faculdades, em sua grande maioria privadas e pelos Institutos Federais, os quais por força de lei necessitam incluir, em sua oferta, cursos de licenciatura, conforme prevê a Lei n 11.892 , de 29 de dezembro de 2008 (BRASIL, 2008).

Em relação aos institutos federais, os cursos superiores a serem ofertados incluem as seguintes possibilidades: cursos superiores de tecnologia; cursos de licenciatura, bem como programas especiais de formação pedagógica visando à formação de professores para a educação básica lem especial nas áreas de ciências e matemática). Quanto à educação profissional propriamente dita, destacam-se cursos de bacharelado e engenharia; cursos de pós-graduação lato-sensu de aperfeiçoamento e especialização; além de cursos de pós-graduação stricto sensu (mestrado e doutorado).

Tudo isso contribui para a ampliação do lócus ${ }^{7}$ da formação de professores, e, em consequência, da diversidade de opções ofertadas, que passam a incluir, além dos cursos presenciais, a modalidade a distância.

Adicionalmente, pode-se afirmar que, apesar da baixa atratividade da profissão, há ainda necessidade de indução de ofertas de cursos de licenciaturas em instituições públicas, já que existem os professores que atuam na educação básica sem nível superior, o que se constitui como uma tarefa que não pode ser excluída da responsabilidade do setor público, em especial nas IES públicas federais (CAMARGO; CASTRO, 2016).

Outra importante questão diz respeito à necessidade de atrair os estudantes para os cursos de licenciatura, já que existem poucos incentivos financeiros para atrair para a carreira docente os bons estudantes do ensino médio, conforme demonstram Louzano, Rocha, Moriconi e Oliveira (2010); neste estudo, os autores chamam atenção para o fato de que, o bom desempenho dos estudantes de países no Programa para Avaliação Internacional de Alunos (PISA2, no inglês) da Organização para a Cooperação e o Desenvolvimento Econômico (OCDE) está intimamente relacionado à atuação de seus professores, o que depende da qualidade da formação para o magistério, o que difere da realidade brasileira, na qual continua sendo necessário o investimento público. 
A seguir, se verá como a oferta de cursos de licenciaturas se dá nas universidades federais criadas no período de 2003 a 2014 , e que estão voltadas para a chamada internacionalização e interiorização, que se constituíram como prioridades assumidas pelo presidente Lula da Silva e a presidente Dilma Rousseff (BRASIL, 2013). Os dados recolhidos dos sítios das universidades mostram a seguinte situação quanto às universidades federais com perfil internacionalizado.

\section{Tabela 2}

Oferta de cursos de graduação e sua relação com os cursos de licenciatura nas universidades federais com perfil internacionalizado

\begin{tabular}{|c|c|c|c|}
\hline Universidades & $\begin{array}{c}\text { Cursos } \\
\text { graduação }\end{array}$ & Licenciatura & $\begin{array}{c}\text { \% Cursos de } \\
\text { licenciatura }\end{array}$ \\
\hline $\begin{array}{c}\text { Universidade Federal } \\
\text { da Integração } \\
\text { Latino-Americana }\end{array}$ & 29 & 6 & 20,7 \\
\hline $\begin{array}{c}\text { Universidade Federal } \\
\text { da Integração } \\
\text { Luso-Afro-Brasileira }\end{array}$ & 15 & 9 & 60 \\
\hline $\begin{array}{c}\text { Universidade Federal } \\
\text { da Fronteira do Sul }\end{array}$ & 19 & 8 & 42,1 \\
\hline $\begin{array}{c}\text { Universidade Federal } \\
\text { do Pampa }\end{array}$ & 42 & 12 & 28,5 \\
\hline
\end{tabular}

Fonte: Sítios das Universidades Federais.

Concernente às quatro universidades criadas com o perfil voltado para a internacionalização, verifica-se que, proporcionalmente, ao número de cursos de graduação, os cursos de licenciatura da Universidade Federal da Integração Luso-Afro-Brasileira - UNILAB respondem por até $60 \%$ da oferta nessa instituição. Isso pode ter relação com a demanda ainda existente no que tange ao número de professores da educação básica com nível superior que atuam na Região Nordeste, e da área de abrangência da UNILAB (Ceará e Bahia).

As demais universidades com esse perfil estão situadas na região Sul, onde duas situações chamam a atenção: a Universidade Federal da Integração 
Latino-Americana - UNILA, e a Universidade Federal da Fronteira do Sul-UFFS, ambas localizadas na Região Sul, com sede no estado do Paraná.

A UNILA é a instituição federal com perfil internacionalizado que registra o menor percentual de oferta em relação aos cursos de licenciatura, $20,7 \%{ }^{8}$, o que indica a existência de outras prioridades por ocasião de sua constituição, o que se evidencia na oferta de 23 cursos de outra natureza que não a licenciatura. Já a UFFS, que inclui, em sua área de abrangência, os três estados da região (Paraná, Santa Catarina e Rio Grande do Sul), tem um percentual de cursos de licenciatura na ordem de $42,1 \%$, o que pode ser considerado satisfatório do ponto de vista da oferta desses cursos e expressa as demandas por formação nesses estados.

Para se entender melhor a situação, recorre-se aos dados que esclarecem sobre a titulação dos professores da educação básica que atuam nos estados da Região Sul. Tem-se a seguinte situação?: nos estados do Rio Grande do Sul, o percentual de professores que atuam na educação básica e que possuem o nível superior é de 98,5\%; já no estado de Santa Catarina, esse percentual é de 78,3\%; e no estado do Paraná é de 86,7\%, o que indica que ainda existe demanda por qualificação de professores em atuação nesses estados.

Sabe-se que, os estados da Região Sul se diferenciam, de forma positiva, na formação de professores da educação básica em relação a outras regiões brasileiras como o Norte e o Nordeste. Isso faz compreender que, apesar de não haver objetivos específicos no Reuni direcionados para a oferta de cursos de licenciatura, ainda existe procura por esses cursos nos estados dessa região. Isso, sobretudo, considerando que os estudantes atraídos por esse tipo de curso provêm de setores economicamente pobres da população, e que qualquer compromisso financeiro assumido por eles, mesmo através de programas de renúncia fiscal às instituições privadas, caso do Prouni ou Fies, acaba comprometendo o reduzido orçamento familiar desses estudantes.

Veja, agora, como a situação se apresenta à oferta dos cursos de licenciatura em relação aos demais cursos de graduação nas universidades federais, criadas com foco na interiorização. 
Expansão da educação superior, cursos de licenciatura e criação das novas universidades federais

\section{Tabela 3}

Oferta nas universidades federais com foco na interiorização de cursos de graduação e de cursos de licenciatura

\begin{tabular}{|c|c|c|c|}
\hline Universidades & $\begin{array}{c}\text { Cursos } \\
\text { ofertados }\end{array}$ & $\begin{array}{c}\text { Cursos de } \\
\text { licenciatura }\end{array}$ & $\begin{array}{c}\% \text { cursos de } \\
\text { licenciatura }\end{array}$ \\
\hline $\begin{array}{c}\text { Universidade Federal de Alfenas } \\
\text { Universidade Fed. dos Vales Jequitinhonha } \\
\text { e Mucuri }\end{array}$ & 31 & 09 & 29,03 \\
\hline Universidade Federal do Triângulo Mineiro & 26 & 10 & 26,3 \\
\hline Universidade Federal Rural do Semi-Árido & 33 & 04 & 12,1 \\
\hline $\begin{array}{c}\text { Universidade Tecnológica Federal do } \\
\text { Paraná }\end{array}$ & 29 & 0 & 0 \\
\hline Fundação Universidade Federal do ABC & 24 & 05 & 20,8 \\
\hline $\begin{array}{c}\text { Fundação Universidade Fed. de Grande } \\
\text { Dourados }\end{array}$ & 34 & 10 & 29,4 \\
\hline $\begin{array}{c}\text { Universidade Federal do Recôncavo da } \\
\text { Bahia }\end{array}$ & 41 & 11 & 26,8 \\
\hline Universidade Federal do Oeste do Pará & 44 & 12 & 27,3 \\
\hline Universidade Federal do Oeste da Bahia & 16 & 6 & 37,5 \\
\hline Universidade Federal do Sul da Bahia & 09 & 05 & 55,5 \\
\hline Universidade Federal do Sul e Sudeste do \\
Pará
\end{tabular}

Fonte: Sítios das Universidades Federais.

Atinente às universidades federais criadas com foco na interiorização, o maior percentual de cursos de licenciatura foi observado na Universidade Federal do Sul da Bahia - UFESBA, onde, dos 9 cursos de graduação ofertados, 5 deles são cursos de licenciatura, correspondendo, assim, a 55\% do total dos cursos. Trata-se de instituição federal recentemente criada, em 2013, em que o currículo dos cursos ofertados são organizados por grandes áreas de conhecimento entendidos como campos de saberes, práticas e tecnologias e por ciclos ( $1^{\circ}$ e $2^{\circ}$ ciclos). Essa organização curricular, própria dos Bacharelados Interdisciplinares, conforme visto, se constitui em uma nova arquitetura acadêmica incentivada pelo Reuni. 
Outro destaque ocorre também na Bahia, na Universidade Federal do Oeste da Bahia, igualmente criada, em 2013, e que era um dos campi da Universidade Federal da Bahia. Nessa IES, dos 16 cursos de graduação ofertados, $\mathrm{O6}$ são cursos de licenciatura, correspondendo a 37,5\% do total.

No estado da Bahia, o percentual de professores atuando na educação básica e com nível superior é de 60,710, o que indica que ainda existe demanda por qualificação de professores em atuação nesse estado, o que se expressa na oferta registrada.

Nenhum curso de licenciatura foi registrado em relação à Universidade Tecnológica Federal do Paraná - UTFPR, a qual, desde 2005, foi transformada em universidade especializada, a partir da estrutura já existente no Centro Federal de Educação Tecnológica do Paraná (Cefet-PR). Essa nova universidade, com cursos de graduação mais direcionados para a área tecnológica, já contava com um lastro acadêmico na área da educação profissional, o que pode ter sido decisivo na definição da oferta de seus cursos.

Depois da UFTPR, vem a Universidade Federal Rural do Semiárido UFERSA, a qual tem origem na Escola Superior de Agricultura de Mossoró, e que ofertava, além da Agricultura, cursos de Medicina Veterinária, Zootecnia e Engenharia Agrícola, das chamadas ciências agrárias. Nessa instituição, dos 33 cursos de graduação registrados, 4 são licenciaturas, o que corresponde $12,1 \%$ do total.

Por último, no período estudado, foi criada a Universidade Federal de Ciências da Saúde, UFCSPA, por transformação da Fundação Faculdade Federal de Ciências Médicas de Porto Alegre, Lei n 11.641 , de 11 de janeiro de 2008 UFCSPA, na cidade de Porto Alegre, que não se encaixa em nenhum dos perfis mencionados anteriormente. Nessa instituição, a oferta registrada é de 15 cursos de graduação e nenhum deles é um curso de licenciatura, o que pode ser explicado pela origem da mesma, criada a partir de uma instituição não universitária voltada para a área das Ciências da Saúde. Como já mencionado, no caso da UTFPR, que tinha uma trajetória diferenciada, em que conta na definição de seus cursos a história anterior dessas IES.

Dessa forma, pode-se dizer que existem situações distintas no que diz respeito à manutenção da oferta dos cursos de licenciatura, sobretudo no que tange às novas instituições com sede no interior dos estados, onde a demanda por formação de professores em nível superior ainda se constitui em um desafio 
Expansão da educação superior, cursos de licenciatura e criação das novas universidades federais

que exige especial atenção por parte do estado brasileiro que não pode se eximir de suas responsabilidades quanto à atração, formação e permanência de professores com um nível de qualificação adequado.

\section{Considerações finais}

Conforme visto, o estudo sobre expansão da educação superior, no Brasil, nesses primeiros anos do século XXI e das novas universidades federais criadas no período, impõe um exercício permanente de monitoramento sobre as mudanças que vem ocorrendo e que reconfiguram desde a concepção até o modus operandi dessas universidades.

que se constatou é que ainda há espaço para a tarefa de formar professores no espaço universitário, como visto nos dados apresentados, em que foram identificadas situações distintas quanto à oferta dos cursos de licenciatura. De modo geral, nas novas instituições com sede no interior dos estados, onde a formação de professores em nível superior ainda se constitui em um desafio, ainda se verifica um percentual expressivo na oferta de cursos de licen268 ciatura, como é o caso dos estados da Bahia (UFESBA) e do Pará (UFOB). Em sua gênese, tais universidades se constituíam como campus da Universidade Federal da Bahia e da Universidade Federal do Pará, e é provável que essa oferta reflita ainda as prioridades assumidas anteriormente nesse momento, já que, como visto, a criação de universidades federais ocorre num contexto de constrangimentos financeiros que atingem o setor público de modo geral.

Entretanto, nas universidades federais onde já havia uma trajetória acadêmico científica diferenciada, caso da UFTPR, UFERSA e da UFCSPA, a oferta desses cursos não está incluída entre as prioridades dessas instituições. Nenhum curso de licenciatura foi registrado nessas novas universidades, já que a UTFPR, que, desde 2005, foi transformada em universidade especializada, a partir do Centro Federal de Educação Tecnológica do Paraná (CefetPR), apresenta cursos de graduação mais direcionados para a área tecnológica. Isso corrobora o entendimento de que o lastro acadêmico na área da educação profissional, pode ter sido decisivo na definição da oferta de seus cursos.

Esse parece ter sido o caso da Universidade Federal Rural do Semiárido - UFERSA, que teve sua origem na Escola Superior de Agricultura de Mossoró, e que ofertava, além da Agricultura, cursos de Medicina Veterinária, 
Zootecnia e Engenharia Agrícola, das chamadas ciências agrárias. Nessa instituição, dos 33 cursos de graduação registrados, 4 são licenciaturas, o que corresponde $12,1 \%$ do total.

Como a essência do público é a universalização do direito, não é possível restringir a oferta da educação superior que a entende como bem privado; na criação de instituições federais de educação superior é necessário reafirmar o entendimento de que a oferta de cursos de graduação constitui um direito, inclusive daqueles que optam por cursos de licenciatura. Entende-se que é necessário adequar a oferta às demandas no campo pessoal e profissional que aproximem as universidades não só das demandas mercadológicas; caso se confirme essa tendência na definição das prioridades do setor público federal, acredita-se que restringir os objetivos e fins dessas universidades a uma lógica mercantil, pode comprometer a existência da universidade como instituição pública estatal, gratuita, laica e de qualidade socialmente referenciada. Um acentuado processo heteronômico associado a novos marcos regulatórios assola as universidades, trazendo um novo modus operandi que prioriza cursos e uma formação voltados para atender aos interesses do mercado, o que acaba por reforçar uma visão pragmática e mercantil da educação superior.

Nessas universidades públicas federais reconfiguradas, pós-REUNI, estão sendo construídas novas arquiteturas acadêmicas nos cursos de graduação e pós-graduação e uma nova cultura acadêmico-institucional, gerando um "mosaico" que precisa ser decifrado.

\section{Notas}

1 A terminologia ensino secundário corresponde à etapa da escolarização destinada aos jovens e adolescente e que se localiza entre o chamado ensino básico e o ensino superior.

2 A terminologia ensino secundário corresponde à etapa da escolarização destinada aos jovens e adolescente e que se localiza entre o chamado ensino básico e o ensino superior. A terminologia ensino secundário, que vigorou no Brasil, corresponde ao atual segmento do ensino Fundamental e Ensino Médio (Lei n 9394/1996).

3 Esse projeto vem sendo desenvolvido desde 2012 pela Rede Universitas/Br e está vinculado ao Observatório da Educação (OBEDUC/CAPES).

4 Programa de Apoio a Planos de Reestruturação e Expansão das Universidades Federais - REUNI, (Decreto No 6.096 de 24 de abril de 2007). Integra o Plano de Desenvolvimento Educacional PDE, (Decreto N 6.095, de 24 de abril de 2007) como uma regulação da política de expansão da educação superior. É um Acordo de Metas ou contrato de gestão entre as universidades e o MEC. 
Expansão da educação superior, cursos de licenciatura e criação das novas universidades federais

5 Compuseram o Grupo de Trabalho: Murilo Silva de Camargo DIFES/SESu/MEC; Cleunice Matos Rehem, DESUP/SESU/MEC; Yara Maia Rauh, UFSC; Derval dos Santos Rosa, UFABC; Murilo Cruz Leal, UFSJ;Eduardo Magrone, UFJF; Naomar de Almeida Filho, UFBA.

6 Universidade Federal do Oeste do Pará, Universidade Federal da Integração Luso-Afro-Brasileira, Universidade Federal do Pampa, Universidade Federal da Fronteira Sul, Universidade Federal de Alfenas, Universidade Federal Rural do Semi-Árido, Universidade Federal do Vale do Jequitinhonha e Mucuri, Universidade Federal do Recôncavo Baiano.

7 Importante lembrar que o Decreto Presidencial n³.276, de 06 de dezembro de 1999, que dispõe sobre a formação em nível superior de professores para atuar na educação básica, definiu como lócus preferencial da formação de professores os Institutos Superiores de Educação.

8 Dados extraídos do sítio http:/ / cultivaeduca.ufrgs.br

9 No momento da produção deste Artigo, tramitavam, no Congresso Nacional brasileiro (março de 2017), as Reformas da Previdência e Trabalhista, retirando direitos históricos da classe trabaIhadora que reagia com manifestações massivas nas capitais do país.

10 Dados extraídos do sítio http:/ / cultivaeduca.ufrgs.br

\section{Referências}

AZEVEDO, Mário Luiz Neves de. Internacionalização ou transnacionalização da educação superior: entre a formação de um campo social global e um mercado de ensino mundiali-

270 zado. Crítica Educativa, Sorocaba, v. 1, n. 1, p. 56-79, jan./jun. 2015.

BANCO MUNDIAL. LAVERDE, Martha. (Coord. Geral da Edição em espanhol). Construir sociedades do conhecimento. Nuevos Desafíos para la Educacion Terciária, Quebecor, World Bogotá S.A., 2003.

BRASIL. Lei n 9394, de 20 de dezembro de 1996. Estabelece as Diretrizes e Bases da Educação Nacional. Diário Oficial [da] União, Poder Executivo, Brasília, DF, 23 dez. 1996, p. 27833-27.841.

Lei 10.260, de 12 de julho de 2001 a. Dispõe sobre o Fundo de Financiamento ao estudante do Ensino Superior e dá outras providências. Diário Oficial [da] União, Poder Executivo, Brasília, DF, 13 jul. 2001. Disponível em: http://www.planalto.gov.br/ccivil_03/Leis/LEIS_2001/L10260.htm. Acesso em: 12 set. 2015.

Lei n 11 .096, de 13 de janeiro de 2005. [Conversão da MPv n 213 , de 2004]. Institui o Programa Universidade para Todos - PROUNI, regula a atuação de entidades beneficentes de assistência social no ensino superior; altera a Lei no 10.891, de 9 de julho de 2004, e dá outras providências. Diário Oficial [da] União, Poder Executivo, Brasília, DF, 14 jan. 2005. Disponível em: <http://www.planalto.gov.br/ccivil_03/_Ato20042006/2005/Lei/L1 1096.htm>. Acesso em: 23 set. 2014. 
Decreto $\mathbf{n}^{\circ} \mathbf{5 . 7 7 3}$, de $\mathbf{9}$ de maio de 2006. Dispõe sobre o exercício das funções de regulação, supervisão e avaliação de instituições de educação superior e cursos superiores de graduação e sequenciais no sistema federal de ensino. Disponível em: <http://www2. mec.gov.br/sapiens/portarias/dec5773.htm>. Acesso em: 24 jan. 2016.

Decreto $\mathbf{n}^{\circ}$ 6.096, de 24 de abril de 2007. Institui o Programa de Apoio a Planos de Reestruturação e Expansão das Universidades Federais - REUNI. Disponível em: http:// portal.mec.gov.br/sesu/arquivos/pdf/diretrizesreuni.pdf. Acesso em: 22 jan. 2016.

Lei $n^{\circ} 11$.892, de 29 de dezembro de 2008. Institui a Rede Federal de Educação Profissional Científica e Tecnológica e dá outras providências. Diário Oficial da República Federativa do Brasil, Brasília, DF, Seção 1, 30 dez. 2008. p. 1.

Lei $\mathbf{n}^{\circ}$ 11.641, de 11 de janeiro de 2008. Dispõe sobre a transformação da Fundação da Faculdade Federal de Ciências Médicas de Porto Alegre - FFFCMPA em Fundação Universidade Federal de Ciências da Saúde - UFCSPA e dá outras providências. Disponível em: http://www.planalto.gov.br/ccivil_03/_Ato2007-2010/2008/Lei/ L1 1641 .htm. Acesso em: 23 set. 2017.

Instituto Nacional de Estudos e Pesquisas em Educacionais Anísio Teixeira. Censo da Educação Superior Brasileira: Resumo Técnico 2012. Brasília: INEP, 2012. Disponível em: <www.inep.gov.br/download/superior/censo/tabelas_resumo_tec_.xls>. Acesso em: 18 mar. 2017

Instituto Nacional de Estudos e Pesquisas em Educacionais Anísio Teixeira. Censo da Educação Superior Brasileira: Resumo Técnico 2013; 2014. Brasília: INEP, 2013. Disponível em:<www.inep.gov.br/download/superior/censo/tabelas_resumo_tec_.xls>. Acesso em: 20 mar. 2017.

Censo da Educação Superior Brasileira. Resumo técnico 2014. Brasília, INEP. Disponível em: www.inep.gov.br/download/superior/censo/tabelas_resumo_tec_.xls. Acesso em: 20 mar. 2017.

SESU/MEC. A democratização e expansão da educação superior no país. 2003-2014. Disponível em: http://portal.mec.gov.br/index.php?option=com_ docman\&view=download\&alias= 16762 -balanco-social-sesu-2003-20 $14 \&$ ttemid=30192 Acesso em: 23 fev. 2016.

CHARLE, Chistophe; VERGER, Jacques. História das universidades. São Paulo: Editora UNESP, 1996. 
Expansão da educação superior, cursos de licenciatura e criação das novas universidades federais

CHARLOT, Bernard; SILVA, Veleida Anahi da. De Abelardo até a classificação de Xangai: as universidades e a formação dos docentes. Educar, Curitiba, n. 37, p. 39-58, maio/ago. 2010.

CHESNAIS, François. A globalização e o curso do capitalismo de fim-de-século. Economia e Sociedade, Campinas, v. 5, p. 1-30, dez. 1995.

FERREIRA, Suely; OLIVEIRA, João Ferreira de. As reformas da educação superior no Brasil e na União Europeia e os novos papéis das universidades públicas. Nuances: estudos sobre educação, Presidente Prudente, v. 17, n. 18, p. 50-67, jan./dez. 2010.

LIMA, Katia. Contra-reforma na educação superior: de FHC a Lula. São Paulo: Xamã, 2007.

LOUZANO, Paula; ROCHA, Valéria; MORICONI, Gabriela Miranda; OlIVEIRA, Romualdo Portela de. Quem quer ser professor? Atratividade, seleção e formação docente no Brasil. Estudos Avaliação Educacional, São Paulo, v. 21 , n. 47, p. 543-568, set./dez. 2010.

MANCEBO, Deise; RIBEIRO, Carla Vaz Santos. Pagamento por performance, avaliação e implicações para o trabalho docente na educação superior pública. In: SILVA JÚNIOR, João dos Reis da Silva; CATANI, Afrânio e CHAVES, Vera Lucia Jacob. Org.) Consequências da mundialização da universidade pública brasileira: pós-graduação, trabalho docente, profissionalização e avaliação. São Paulo: Xamã, 2012.

MANCEBO, Deise; MAUÉS, Olgaises. Cabral; CHAVES, Vera Lúcia Jacob. Crise e reforma do Estado e da universidade brasileira: implicações para o trabalho docente. Educar em Revista, Curitiba, n. 28, p. 37-53, jul./dez. 2006.

MEDEIROS, Luciene das Graças Miranda. O REUNI - Uma nova regulação da política de expansão da educação superior: o caso da UFPA. 2012. 31 lf. Tese (Doutorado em Educação) - Programa de Pós-Graduação em Educação, Universidade Federal do Pará, Belém, 2012.

MINDAL, Clara Brenner; GUÉRIOS, Etiènne Cordeiro. Formação de professores em instituições públicas de ensino superior no Brasil: diversidade de problemas, impasses, dilemas e pontos de tensão. Educar em Revista, Curitiba, n. 50, p. 21-33, out./dez. 2013.

MOROSINI, Marília Costa. Educação superior e transnacionalização. Avaliação/qualidade/acreditação. In: FÁVERO, Maria de Lourdes; MANCEBO, Deise (Org.). Política, avaliação e trabalho docente. São Paulo: Cortez, 2004. 
McCOWAN, Tristan; SCHENDEL, Rebecca. A mudança do papel da universidade e seu impacto na sociedade em países de baixa renda. In: SILVA JUNIOR, João dos Reis; SOUSA; AZEVEDO, Mário Luiz Neves de; CHAVES, Vera Lúcia Jacob. Internacionalização, mercantilização e repercussões em um campo de disputa. Belo Horizonte: Fino Traço, 2015.

Brasil Século XXI: propostas educacionais em disputa. In: LOMBARDI, José Claudinei; SANFELICE, José Luís (Org.). Liberalismo e educação em debate. Campinas: Autores Associados/Histedbr, 2007.

PAULANI, L. Brasil Delivery: servidão financeira e estado de emergência econômico. São Paulo: Boitempo, 2008.

PEREIRA, Elizabete Monteiro Aguiar. A universidade da modernidade nos tempos atuais. Avaliação, Campinas/Sorocaba, v. 14, n. 1, p. 29-52, mar. 2009.

SGUISSARDI, Valdemar. Estudo diagnóstico da política de expansão da (e acesso à) educação superior no Brasil, 2002-2012. Brasília: Edital n. $051 / 2014$ SESU; Projeto de Organismo Internacional - OEl; Projeto OEI/BRA/10/002, 2014

Prof ${ }^{a}$. Dr ${ }^{a}$. Arlete Maria Monte de Camargo Universidade Federal Pará | Belém Instituto de Ciências da Educação

Programa de Pós-Graduação em Educação Grupo de Estudo e Pesquisa de Política Educacional Formação e Trabalho Docente - GESTRADO Grupo de Estudos e Pesquisas sobre Educação Superior - GEPES Vice Coordenadora do Subprojeto 2 do OBEDUC 201 2-20 16 sobre Políticas de Expansão da Educação Superior no Brasil Pós- LDB/96 E-mail | ammcamargo@gmail.com

Profa. Dra. Luciene das Graças de Miranda Medeiros Universidade Federal do Pará | Grupo de Estudo e Pesquisa de Política Educacional Formação e Trabalho Docente - GESTRADO Grupo de Estudos e Pesquisas sobre Educação Superior - GEPES 
Artigo

Expansão da educação superior, cursos de licenciatura e criação das novas universidades federais

Integra o Subprojeto 2 do OBEDUC/Rede Universitas/BrPolíticas de Expansão da Educação Superior no Brasil pós LDB/96 E-mail | lucienemm@oi.com.br

Recebido 28 set. 2017 Aceito 16 nov. 2017 